DOI: $10.47456 / k r k r . v 1 i 5.32448$

\title{
As contribuições do PIBID Artes Visuais/UFES para a formação docente
}

\author{
Contributions of PIBID Visual arts/UFES for teaching training \\ Maira Pêgo de Aguiar
}

Resumo: O presente artigo discute as contribuições para a formação profissional e humana dos bolsistas de graduação, supervisão e coordenação do Programa Institucional de Bolsa de Iniciação à Docência - Pibid, mantido pela Capes, mais especificamente na atuação junto ao Subprojeto de Artes Visuais da Universidade Federal do Espírito Santo - Ufes. Tem como objetivo discutir os diferentes aspectos da formação para a docência desses três atores que tornam possível o trabalho no Pibid, a partir de reflexões feitas ao longo da vigência do último edital do Pibid Capes de agosto de 2018 a janeiro de 2020, sob minha coordenação. O texto destaca como as interações entre os diferentes atores do programa promoveram um processo de formação docente dinâmico, baseado na reflexão, na pesquisa e na ação, promovendo ainda a formação humanística desses diferentes atores que passaram a perceber a escola como espaço de potência para a formação estética de crianças, adolescentes e jovens.

Palavras-chave: Pibid Artes Visuais. Formação Docente. Decência.

Abstract: The following article discuss the contributions towards the professional and humane formation of the graduation scholars, supervisors and coordinators of the Institutional of Scholarship of teaching initiation Program -PIBID, maintained by Capes, more specifically in the field of the subproject od visual arts from the Federal University of Espirito Santo - Ufes. It has as an objective to discuss the different aspects of the formation to teaching of these three factors that make possible the work on the program, starting reflections made along the validity of the last Pibid Capes official notice from august 2018 to January 2020, under my coordination. The text highlights how the interactions between the different actors in the program promoted a dynamic teacher training process, based on reflection, research and action, promoting the humanistic training of these different actors who started to perceive the school as a space of power for the aesthetic formation of children, adolescents and young people.

Keywords: Pibid Visual Arts. Teacher Education. Decency.

\section{Introdução}

Considero importante iniciar esta conversa destacando a já comprovada relevância do Pibid para a formação docente no Brasil, conforme apontam dados levantados pelo Fórum Nacional de Coordenadores do Pibid - Forpibid a partir de 38.000 respostas à questionários enviados a bolsistas de Iniciação à Docência, Supervisores, Coordenadores de área e institucionais. Além desses dados, a pesquisa considerou ainda dissertações, teses, artigos em periódicos e trabalhos apresentados em eventos que tratam de temáticas ligadas a 
atuação do Pibid nas diferentes regiões do Brasil. O documento foi publicado pelo Forpibid em 20 de setembro de 2019, e aponta alguns aspectos:

Uma significativa melhoria da qualidade de ensino nas escolas promovida pelo compartilhamento do trabalho entre os bolsistas que, sob a orientação dos Coordenadores de Área e com o apoio dos Professores Supervisores, tem resultado em "[...] aulas mais dinâmicas, uso de metodologias alternativas, projetos e atividades práticas, o que tem provocado maior interesse e motivação por parte dos alunos da escola" (p.2).

Uma crescente atratividade para o magistério e um reforço da opção de jovens pela licenciatura pois,

[...] a oportunidade de entender e viver a escola, o entusiasmo de outros "pibidianos", a existência de projetos com significado fazem com que eles se voltem para a docência e atribuam valor à atividade de ensino na educação básica. (p.2)

Aponta ainda que o ingresso na universidade passa a ser um projeto dos estudantes da educação básica a partir das experiências vividas por estes estudantes com os bolsistas do Pibid em suas escolas nas quais eles percebem uma real oportunidade de ingressar no ensino superior, o que, em muitos casos, era uma perspectiva inexistente nas comunidades mais pobres.

Outro relevante aspecto destacado no documento do Forpibid refere-se à valorização, o fortalecimento e o aperfeiçoamento das licenciaturas

[...] propiciada pela articulação teoria-prática, pela aproximação dos Licenciandos Bolsistas e das IES com o contexto escolar e pela participação dos bolsistas em atividades como grupos de estudo, debates, reuniões, eventos. (p.2-3).

Foi possível observar que o Pibid deu aos cursos de licenciatura visibilidade nas Instituições de Ensino Superior e fora dela, passando a atrair mais estudantes e ainda, reduziu a evasão nos cursos pois proporciona contato com a docência desde o início da graduação. Observou-se também que houve um aumento na motivação dos bolsistas para a realização das atividades dos cursos e que a atuação do Pibid levou muitos cursos de licenciatura a reverem suas práticas. 
Os dados apontam a importância do suporte financeiro para os licenciandos em sua maioria de baixa renda, que necessita de custeio para sua permanência e dedicação ao curso. As bolsas permitem aos licenciandos dedicarem tempo para vivenciar experiências que não teriam oportunidade sem elas, possibilitando-lhes mais presença na universidade, assim como, em outras oportunidades de formação ocorridas na IES e também fora dela.

As mudanças ocorridas nas escolas também são um aspecto importante destacado no documento, pois

[...] o trabalho realizado pelo PIBID fomenta o protagonismo dos alunos da escola básica, seja por considerar as relações na escola que permitem aprendizagens diversificadas e diferenciadas, seja pela contribuição dos Supervisores nas atividades pedagógicas e formativas de futuros professores. Há otimização da utilização de bibliotecas e espaços de leitura $(70,8 \%)$, a (re) abertura e/ou melhoria na utilização das salas de mídias e informática $(64,8 \%)$, dos laboratórios de ciências $(59,6 \%)$ e dos espaços de produção artística $(58,1 \%)$. (p.3)

O Forpibid destaca ainda que a participação no Pibid favorece a formação continuada tanto dos docentes do ensino superior quanto dos docentes da educação básica. Foi observado a partir das ações conjuntas entre escolas e universidades uma busca, desses atores, por novos conhecimentos e novas metodologias de ensino. Nesse sentido, os dados indicaram que essa aproximação acabou por estimular a pesquisa, aumentando assim a produtividade de artigos em periódicos, teses e dissertações escritos por docentes coordenadores e também por docentes da educação básica que atuam como supervisores nos projetos do Pibid.

Os aspectos destacados no documento do Forpibid na análise da atuação dos projetos de Pibid pelo país, foram igualmente percebidos ao longo do trabalho com o Pibid Artes Visuais na Ufes no período de agosto de 2018 a janeiro de 2020, no convívio com os bolsistas ID, nas conversas com os professores supervisores, nas atividades realizadas nas escolas. É sobre essa experiência que me debruço a seguir para tratar especificamente sobre a formação profissional e humana dos bolsistas de graduação, supervisão e coordenação do Pibid Artes Visuais da Universidade Federal do Espírito Santo - Ufes. 


\section{A questão da formação no PIBID Artes Visuais Ufes: Uma formação decente para a docência na contemporaneidade}

Gostaria de iniciar esta conversa tratando do que considero a formação docente ideal, ou seja, uma formação docente para a atuação na contemporaneidade, ou uma formação decente para a docência.

É preciso considerar que o sujeito contemporâneo difere em grande medida do sujeito moderno, de pensamento estruturado, formado em sua maioria pela educação escolar/acadêmica. É claro que há diferentes contextos: urbanos, rurais, grandes centros, periferias, com condições de maior ou menor acesso aos bens culturais/tecnológicos, mas, de modo geral, o sujeito contemporâneo difere sim, do sujeito moderno! O sujeito contemporâneo, está imerso em uma sociedade hiper informada, hiper estimulada, ultra imagética. Larrosa (2005, p.20) afirma:

Nós somos sujeitos ultra-informados, transbordantes de opiniões e superestimulados, mas também sujeitos cheios de vontade e hiperativos. $E$ por isso, porque sempre estamos querendo o que não é, porque estamos sempre em atividade, porque estamos sempre mobilizados, não podemos parar.

O autor caracteriza o sujeito contemporâneo a partir do contexto social, político e cultural da atualidade e explora a ideia de que, nesse contexto de hiper estimulação, muitas vezes a experiência é inviabilizada pelo excesso de informação, de opinião, de trabalho. Na mesma dissertação sobre a temática da experiência, Larrosa propõe pensarmos a educação a partir de um par diferente do que foi pensado nas sociedades modernas, segundo o qual costuma-se pensá-la "[...] do ponto de vista da relação entre a ciência e a técnica ou, às vezes, do ponto de vista da relação entre teoria e prática" (p.20). O autor afirma:

O que vou lhes propor aqui é que exploremos juntos outra possibilidade, digamos que mais existencial (sem ser existencialista) e mais estética (sem ser esteticista), a saber, pensar a educação a partir do par experiência/sentido. (p.20)

É a partir desta proposta de Larrosa (2005) que gostaria de explorar minha concepção de formação docente ideal, ou seja, de uma formação decente para a docência, mais especificamente para a docência do ensino da 
Arte. Sobre a decência na docência, gostaria de ressaltar que, embora tenha sido escrito na modernidade, a concepção de Paulo Freire sobre formação docente me parece extremamente contemporânea.

Paulo Freire (1996) considera a educação o caminho para a libertação do sujeito da manipulação e da opressão por outros sujeitos. Para o autor, a educação tem como função a leitura e a transformação do mundo pelos sujeitos que nele vivem. E só é possível educar num contexto de autonomia, nesse sentido destaca que ensinar não é transferir conhecimento e para que isso se dê na prática é preciso que o docente reconheça que ensinar exige consciência do inacabamento, exige o reconhecimento de que somos seres condicionados, exige respeito à autonomia do ser do educando, exige bom senso, humildade, tolerância e luta em defesa dos direitos dos educadores, exige apreensão da realidade, alegria e esperança também! Para ser docente é preciso reconhecer que ensinar exige a convicção de que a mudança é possível, para isto é preciso ser curioso.

A concepção de formação docente de Paulo Freire aponta para saberes contemporâneos tão necessários às relações educativas quanto os conhecimentos específicos de cada área de conhecimento que são trabalhados na escola. Para o autor, ensinar é uma especificidade humana que exige segurança, competência profissional, generosidade e comprometimento, exige compreender que a educação é uma forma de intervenção no mundo, que é preciso dar liberdade a quem aprende e ao mesmo tempo ter autoridade para poder ensinar/aprender, ensinar exige tomada consciente de decisões, exige saber escutar. Para ensinar é preciso reconhecer que a educação é ideológica e que, portanto, exige disponibilidade para o diálogo e acima de tudo, exige que queiramos bem aos nossos educandos. Para adquirirmos os saberes necessários à educação, segundo Paulo Freire, é preciso pensá-la a partir do par experiência/sentido como o propõe Jorge Larrosa.

Nesse ponto gostaria de retomar alguns dos aspectos apontados pelo Forpibid em sua pesquisa que tratam das contribuições do Pibid para a formação geral de seus atores e que indicam que os saberes descritos por Paulo Freire têm se construído no bojo das relações entre os atores do Pibid. 
Um deles aponta para a significativa melhoria da qualidade de ensino nas escolas o que pode ser explicado pela diversidade de metodologias de trabalho promovida pelo programa junto às salas de aula onde atuam seus supervisores, nas quais o protagonismo dos estudantes da escola altera a dinâmica das relações dando mais espaço para o diálogo, principalmente se considerarmos que os bolsistas, geralmente ingressantes no curso, tem quase a mesma idade de muitos dos estudantes da educação básica. Essa aproximação acaba por favorecer o debate sobre temas atuais, entre eles as manifestações artísticas na contemporaneidade.

Diálogos que só são possíveis se há, por parte do docente, o princípio freireano de respeito à autonomia do ser do educando, se há o reconhecimento de que somos seres condicionados pela cultura, mas, não determinados por ela e, assim, conversar sobre a cultura, debater sobre suas manifestações na arte faz muito mais sentido do que trazer conteúdos prontos, que não podem ser questionados ou discutidos. É pensar assim, a educação a partir da ideia de que é importante atribuir sentido às experiências vividas no contexto do ensino da Arte.

Experiências carregadas de sentido, foram observadas ao longo da vigência do último edital do Pibid Artes Visuais Ufes, as quais trouxeram- nos demandas de elaboração e manutenção de formação continuada para os docentes supervisores que se sentiam desafiados pelos novos conteúdos propostos pelos bolsistas de ID, confirmando assim o que as pesquisas do Forpibid apontaram, a partir das ações conjuntas entre escolas e universidades, uma busca, desses atores, por novos conhecimentos e novas metodologias de ensino. Confirmando ainda mais um princípio do saber docente, colocado por Paulo Freire que é, além da competência profissional, a generosidade e o comprometimento com o educando. A compreensão de que a educação é uma forma de intervenção no mundo, para nele viver melhor, e que para isso é preciso saber escutar o educando, entender suas necessidades, legitimar sua curiosidade e buscar instrumentos para ajuda-los a ampliarem seus conhecimentos. 
Larrosa (2005, p.24) destaca que "o sujeito da experiência é um sujeito 'ex-posto'”:

Do ponto de vista da experiência, o importante não é nem a posição (nossa maneira de pormos), nem a "o-posição" (nossa maneira de opormos), nem a "imposição" (nossa maneira de impormos), nem a "proposição" (nossa maneira de propormos), mas a "exposição", nossa maneira de "ex-pormos", com tudo o que isso tem de vulnerabilidade e de risco. Por isso é incapaz de experiência aquele que se põe, ou se opõe, ou se impõe, ou se propõe, mas não se "ex-põe". É incapaz de experiência aquele a quem nada the passa, a quem nada the acontece, a quem nada Ihe sucede, a quem nada o toca, nada Ihe chega, nada o afeta, a quem nada o ameaça, a quem nada ocorre.

A docência em tempos de hiper informação exige do sujeito a consciência de que não será capaz de dominar todo o conhecimento de sua área de formação, de que, talvez, ou muito provavelmente, diferente do que pensava o professor moderno, detentor do conhecimento, seus educandos saberão conteúdos que ele não sabe. Nesse sentido, a vivência dos licenciandos no Pibid inaugura uma nova dinâmica de ensino e de aprendizagem nos cursos de graduação para a docência, uma vez que coloca o estudante da licenciatura num duplo papel, ele é ao mesmo tempo, e no mesmo tempo/lugar, discente e docente. Está assim, numa condição de dupla exposição, pois, para formar-se precisa abrir-se para a formação sendo aprendiz do espaço da escola ao atuar como professor, supervisionado, claro, nesse espaço. O exercício da docência na dinâmica do Pibid, exige do sujeito humildade para expor-se!

A prática da docência no exercício da aprendizagem, não somente com os professores supervisores, mas também como os estudantes da educação básica é uma das características do Pibid Artes Visuais Ufes. Considero uma importante característica, pois a consciência do inacabamento nos constitui mais flexíveis, mais atentos ao contexto e ao outro, mais humildes, faz do aprendizado da docência também um aprendizado de decência como nos desafia Paulo Freire. 


\section{Contribuições do Pibid Artes Visuais Ufes para a formação inicial e formação continuada}

Destaco aqui a relevante contribuição da escola para a formação dos licenciandos, uma vez que este é o espaço prioritário de ensino de Artes no Brasil para a grande maioria das crianças e adolescentes. No âmbito do ensino das Artes Visuais na Ufes a importância do Pibid para a formação profissional dos bolsistas de graduação vem se consolidando ao longo do tempo, numa crescente afirmação do seu papel formativo para a docência dos licenciandos dos cursos de Artes Visuais Integral e Noturno.

À medida que promove a aproximação dos licenciandos com o ambiente escolar o Pibid, na sua dinâmica de interação entre a universidade, a escola e, muitas vezes, também a comunidade, desvela para os licenciandos o cotidiano da escola nas suas minúcias. Coloca-os em contato com as dificuldades enfrentadas pelos professores nas suas atividades cotidianas na condução da disciplina de Artes, da escolha de materiais, de temáticas, confronta-os sobre as possibilidades de colocar em prática suas expectativas sobre a docência, frustra-os, por vezes, inviabiliza suas escolhas, suas falas. Nesse sentido, no retorno à Universidade, nos encontros de formação, em diálogo com outros bolsistas que vivenciam outras realidades escolares, a partilha das experiências provoca amplas possibilidades de discussão sobre diferentes temáticas que se colocam na urgência do debate.

Envolve nesse momento, além dos bolsistas de graduação, também os supervisores e o coordenador em demandas pela compreensão de questões contemporâneas sobre a escola, a docência e sobre a própria arte, em muitos casos sobre questões humanas, de direitos, de culturas que extrapolam nossa competência e nos impulsionam à busca de outros sujeitos que nos ajudem nesse processo formativo.

A mesma dinâmica de interação citada acima, entre a universidade, a escola e comunidade surpreende os bolsistas, pois, no mesmo espaço/tempo do cotidiano escolar, o Pibid acaba por promover o encontro desses, hoje licenciandos, com sujeitos que ocupam um lugar há pouco ocupado por eles, a educação básica, provocando um deslocamento do olhar que antes focado na 
aprendizagem, quase ou nunca percebia a docência e agora, no papel de futuro docente, percebe as dificuldades também legítimas do ensino. Encontros que demandam dos bolsistas, iniciativas antes esperadas do professor, atitudes de cooperação, iniciativas de propostas, ações a serem tomadas rapidamente, no calor da hora! Experiências de formação que transbordam para experiências de vida promovendo assim o desejo por mais experiências similares. Larossa (2005, p.24) descreve um sujeito da experiência feito:

\begin{abstract}
Esse sujeito que não é o sujeito da informação, da opinião, do trabalho, que não é o sujeito do saber, do julgar, do fazer, do poder, do querer. Se escutamos em espanhol, nessa língua em que a experiência é "o que nos passa", o sujeito da experiência seria algo como um território de passagem, algo como uma superfície sensível que aquilo que acontece afeta de algum modo, produz alguns afetos, inscreve algumas marcas, deixa alguns vestígios, alguns efeitos. Se escutamos em francês, em que a experiência é "ce que nous arrive", o sujeito da experiência é um ponto de chegada, um lugar a que chegam as coisas, como um lugar que recebe o que chega e que, ao receber, Ihe dá lugar. $E$ em português, em italiano e em inglês, em que a experiência soa como "aquilo que nos acontece, nos sucede", ou "happen to us", o sujeito da experiência é sobretudo um espaço onde têm lugar os acontecimentos. Em qualquer caso, seja como território de passagem, seja como lugar de chegada ou como espaço do acontecer, o sujeito da experiência se define não por sua atividade, mas por sua passividade, por sua receptividade, por sua disponibilidade, por sua abertura.
\end{abstract}

Com o objetivo de constituírem-se em sujeitos da experiência, os bolsistas do Pibid Artes Visuais Ufes se colocam em abertura para o diálogo com outras áreas de conhecimento a partir das demandas que recebiam em sua atuação na escola. Nesse sentido, ao longo do período de vigência do edital 2018, foram realizados quatro encontros de formação que buscaram articular formação inicial, para os licenciandos e formação continuada, para os professores da educação básica, que, além dos supervisores do Pibid, desejassem participar dos debates.

Os encontros formativos, denominados Pibid Artes Visuais Convida, trouxeram para o contexto/espaço da universidade as demandas da educação básica a partir das reflexões de especialistas, pesquisadores e artistas 
escolhidos pelos bolsistas de graduação, a partir de pesquisas realizadas sobre as temáticas que impunham sua relevância e a necessidade de seu entendimento ou aprofundamento.

O primeiro evento realizado pelo grupo discutiu a educação especial, suas origens na escola pública, legislação atual e direitos da criança e do adolescente com deficiência na escola. Assim, o Pibid Artes Visuais Convida inaugurou em agosto de 2018 os eventos com a palestra da professora Dra Girlene Gobete, servidora da Secretaria de Municipal de Educação de Vitória, da divisão de políticas educacionais. A demanda pelo tema surgiu nas conversas que tivemos nos encontros semanais de planejamento, na universidade, nos quais foi possível perceber a insegurança dos bolsistas ao lidarem com crianças e adolescentes com deficiências.

Depois da palestra, a professora nos encaminhou materiais sobre 0 tema que foram estudados e debatidos em, pelo menos, três encontros seguintes. Este encontro promoveu no grupo uma mudança no modo de perceber o sujeito com deficiência, um deslocamento do olhar, antes, focado na limitação que passou a partir daí, a enxergar as possibilidades desses sujeitos, focando então na busca por estratégias diversificadas para o ensino das artes. Estratégias que promovessem a sua inclusão, que lhes permitissem perceberem-se capazes, criativos, sujeitos de direitos.

O segundo Pibid Artes Visuais Convida debateu com o artista e professor, Dr. Marcos Paulo Martins, os processos de criação artística e as possibilidades de trabalho criativo com as crianças. Em palestra intitulada "Envoltórios" ocorrida em 28 de novembro de 2018, no auditório do Cemuni III, Centro de Artes da Ufes, debatemos sobre as possibilidades de criação artística no âmbito da academia e da escola a partir das pesquisas do professor sobre performance. A temática foi sugerida pelos bolsistas que atuavam no Ensino Fundamental e desejavam compreender melhor os processos criativos das crianças nas classes de período integral. Todo o evento foi organizado pelo grupo de bolsistas que contou com a presença de uma das professoras supervisoras, com estudantes de graduação dos cursos 
de Licenciatura em Artes Visuais e também do bacharelado em Artes Plásticas da Ufes.

Os relatos do professor nos deram uma perspectiva mais abrangente das possibilidades de criação e deram aos bolsistas muitas ideias para os trabalhos que foram, posteriormente, desenvolvidos com as crianças da educação integral, no contra turno da escola e que demandavam novas propostas de trabalho, diferentes das que essas crianças vivenciavam nas aulas de artes, no horário regular.

Em 27 de março de 2019, também no auditório do Cemuni III, Centro de Artes participamos de uma roda de conversa com a professora Sarita Faustino sobre questões étnico-raciais no cotidiano da Educação Básica, no terceiro Pibid Artes Visuais Convida. A professora, que atua na Educação Infantil na rede municipal de Vitória e possui grande experiência com os estudos e debates acerca das questões étnico-raciais no contexto da Ed. Infantil, abordou as relações de racismo que passam a fazer parte da vida da criança ainda na infância quando ingressa na escola. A temática foi sugerida pelos bolsistas que atuavam na Educação Infantil e observaram manifestações de racismo vindas de crianças bem pequenas. Mais uma vez, tivemos a presença de uma professora supervisora e estudantes de graduação de outros cursos.

As discussões acerca do racismo na infância foram enriquecidas por relatos dos próprios bolsistas de graduação, negros, que descreveram situações de discriminação, constrangimento e humilhação sofridas ao longo de suas infâncias na escola. A discussão sobre este tema foi de grande relevância para a formação dos bolsistas e retornou em vários momentos durante a vigência do edital, transbordando para os espaços da universidade nos quais, vemos com pesar a reprodução da lógica racista nas relações entre estudantes e professores. A temática foi, de certa forma, abordada também no quarto encontro de formação do Pibid Artes Visuais, a partir das pesquisas da professora Ms. Mara Pereira dos Santos.

O quarto Pibid Artes Visuais Convida, discutiu a temática da arte contemporânea na palestra dada pela professora Ms. Mara Pereira dos Santos intitulada "Educação e Arte Anticoloniais: Corpos e territórios políticos" ocorrida 
em 05 de junho de 2019, na sala 12 do Cemuni II, Centro de Artes, Ufes. A professora apresentou suas pesquisas de doutorado sobre arte performance que usa o corpo para discutir questões de gênero e sexualidade.

A temática foi sugerida pelos bolsistas que atuavam no Ensino Médio a partir das inquietações apresentadas pelos bolsistas nas vivências com os adolescentes e jovens do Ensino Médio. A palestra possibilitou uma articulação das discussões feitas a partir dos estudos feitos após a palestra da professora Sarita Faustino sobre as relações étnico-raciais na escola.

Ao debatermos as questões de gênero e sexualidade houve grande demanda por trazer a questão do racismo à conversa, bem como as implicações da negritude para o sujeito não heterossexual. Assim como no terceiro encontro, as discussões foram enriquecidas pelos relatos de alguns bolsistas, não heterossexuais, sobre suas experiências na infância e na juventude numa sociedade heteronormativa. Alguns bolsistas manifestaram o desejo de apresentar suas produções artísticas sobre a temática, ao grupo. Isto fizemos em dois encontros que se seguiram ao quarto Pibid Artes Visuais Convida, nos quais, buscamos uma dinâmica mais descontraída, compartilhamos lanches em momentos mais intimistas que proporcionaram grande interação.

As discussões oportunizadas pelos encontros de formação Pibid Artes Visuais Convida foram essenciais para a constituição do perfil de formação do Pibid Artes Visuais Ufes pois, ajudaram na reflexão das práticas vivenciadas pelos bolsistas de graduação e de supervisão, estabelecendo entre eles uma relação de parceria muito mais do que de tutoria, reflexões iniciadas por conhecimentos da experiência que de alguma forma tocaram os bolsistas, causaram-Ihes incomodo e os impulsionaram a busca de novos conhecimentos que lhe dessem subsídios para novas práticas.

\section{Considerações Finais}

lavelberg (2003) ao tratar da complexidade inerente à formação de professores de arte destaca a importância de se criar uma cultura de reflexão sobre os conteúdos abordados no curso de graduação, uma vez que a 
transposição desses, acriticamente, para as práticas de ensino não é suficiente para promover uma aprendizagem significativa em arte.

A autora destaca que a "[...] prática reflexiva se opõe à submissão" (p.64), nesse sentido, afirma que conteúdos da dimensão cultural do licenciando, são tão importantes quanto os conteúdos das dimensões educacionais e organizacionais pois, a partir da compreensão crítica da dimensão cultural e de seus impactos na formação da subjetividade dos sujeitos, é possível confrontar as práticas que promovam a autonomia do professor com aquelas que tendam a compreendê-lo como mero reprodutor de conhecimentos.

A partir do que destaca lavelberg (2003) e das experiências descritas até aqui, ousamos dizer que o processo formativo dos bolsistas do Pibid Artes Visuais Ufes, edital 2018, levou ao licenciando, bolsista uma perspectiva de formação profissional crítica, contextualizada e colaborativa, na medida em que possibilitou a concretização da proposta de Larrosa, de pensar a educação a partir do par experiência/sentido.

Destacamos que, nos encontros formativos, os bolsistas tiveram a liberdade de conduzir as propostas de aprofundamento de temas, elencando coletivamente as questões da dinâmica da escola que deveriam ser debatidas e incluíram nesses espaços/tempos seus professores supervisores. Colocandose numa perspectiva de abertura, despojando-se de preconceitos, expondo-se às experiências que tanto a docência quanto a discencia decentes exigem, os bolsistas se apropriaram aos poucos da sua própria formação, dando-lhe o foco e o tom conforme sentiam-se desafiados a conhecer.

Esse deslocamento de papeis demandou dos professores supervisores um outro olhar sobre os bolsistas de graduação, uma vez que eles, supervisores, tinham como papel o de formadores. Este movimento só foi possível pela dinâmica formativa adotada, de diálogo constante, de disposição para a escuta e abertura para a crítica. Desse modo, é preciso destacar a importância de um professor que respeite a autonomia de seu educando, que reconheça a relevância do saber do educando e que tenha a humildade de aprender com ele, pois nada teria sido possível se os professores supervisores 
não tivessem uma perspectiva freireana de educação, se não primassem pela decência que a responsabilidade da função lhes exigiu.

Devo me colocar também nesta avaliação, como sujeito da experiência que também sou! Tive minha docência e minha subjetividade transformadas pela experiência junto aos demais bolsistas do Pibid Artes Visuais Ufes. Nossas discussões me fizeram mais atenta aos contextos diferentes dos meus, nossas discordâncias me fizeram mais paciente em relação a outros pontos de vista, nossas angústias me fizeram mais flexível diante das certezas acadêmicas.

Tivemos momentos de trocas que evidenciaram a legitimidade do diálogo como modo de formação, da escuta como modo de sensibilização para a realidade do outro e que a realidade do outro cabe perfeitamente no contexto de formação profissional. A realidade do outro, seja ele estudante da educação básica ou do ensino superior, seja ele professor da educação básica ou do ensino superior atravessa esse sujeito e Ihe dá as lentes pelas quais ele enxerga o mundo. Nesse sentido, ouso afirmar que nossa capacidade de visão foi ampliada! Nossas relações de afeto perduram mesmo tendo findado o projeto, isso é reflexo da decência que se construiu nesse processo de formação não somente profissional, mas, sobretudo, humano!

\section{Agradecimentos}

Agradeço à CAPES pelas bolsas concedidas aos licenciandos, supervisores e coordenadora do Pibid Artes Visuais - Ufes. Sem as bolsas não teria sido possível realizar os trabalhos que muito contribuiu para a formação desses sujeitos!

\section{Referências}

FREIRE, Paulo. Pedagogia da Autonomia: saberes necessários à prática educativa. São Paulo: Paz e Terra, 1996.

IAVELBERG, R. Para gostar de aprender arte: sala de aula e formação de professores. Porto Alegre: Artmed, 2003. 
LARROSA, J. Notas sobre a experiência e o saber da experiência. II Congresso Internacional de Educação, Campinas, 2005.

FORPIBID - RP. Pibid e Residência Pedagógia: seu potencial para a educação e para a formação de professores com mais qualidade. Fortaleza, 20 de dezembro de 2019.Sobre o (a) autor (a)

\section{Maira Pêgo de Aguiar}

maira.aguiar@ufes.br

Graduada em Educação Artística pela Universidade Federal do Espírito Santo (1992). Especialista em Psicopedagogia pela SABERES/UNICID (2001). Mestre em Educação pelo Programa de Pós-Graduação em Educação da Universidade Federal do Espírito Santo (2004). Doutora pelo mesmo Programa (2010). Professora adjunta da Universidade Federal do Espírito Santo, no Departamento de Teoria de Arte e Música, Centro de Artes. Coordenadora do curso de Artes Visuais da Ufes desde 2016. Representante dos cursos de Licenciatura do Centro de Artes na Câmara Central de Graduação da Ufes. Coordenadora do Pibid/Artes Visuais/Ufes. 